\title{
Muscle fibre type shifting in the vastus lateralis of patients with COPD is associated with disease severity: a systematic review and meta-analysis
}

\author{
Harry R Gosker, Maurice P Zeegers, Emiel F M Wouters, Annemie M W J Schols
}

Thorax 2007;62:944-949. doi: 10.1136/thx.2007.078980

See end of article for authors' affiliations

Correspondence to: Dr H R Gosker, Department of Respiratory Medicine, NUTRIM, Maastricht University, P O Box 616, 6200 MD Maastricht, The Netherlands; h.gosker@pul. unimaas.nl

Received 1 February 2007 Accepted 15 May 2007 Published Online First 25 May 2007
Background: Skeletal muscle dysfunction is a common feature in chronic obstructive pulmonary disease (COPD) which is associated with intrinsic muscular abnormalities. One of the most consistently reported alterations is a shiff from fibre type I to II in the vastus lateralis of these patients. Surprisingly, the relationship between this shift and the severity and phenotype of COPD remains unclear. A study was conducted to determine whether vastus lateralis muscle fibre type proportions are associated with COPD disease severity and to provide reference values for the proportions of fibre types in the vastus lateralis in COPD.

Methods: A systematic review and a meta-analysis were conducted in which muscle fibre type data and markers of disease severity were collected from the literature.

Results: The forced expiratory volume in $1 \mathrm{~s}\left(\mathrm{FEV}_{1}\right)$, the ratio of $\mathrm{FEV}_{1}$ to forced vital capacity $(\mathrm{FVC})$ and body mass index were positively associated with the proportion of type I fibres in COPD. A proportion of $51 \%$ for vastus lateralis fibre type I and 13\% for fibre type IIX were calculated from the combined data as normal values for patients with typical GOLD stage 3-4 COPD aged 60-70 years. Based on these reference values, a proportion of fibre type I $<27 \%$ and of fibre type IIX $>29 \%$ were defined as pathologically abnormal.

Conclusions: This review sheds new light on the relationship between skeletal muscle abnormalities and important hallmarks of the disease in severe COPD, and identifies absence of data in GOLD stages 1-2. This review also provides reference values on fibre type composition for diagnostic purposes in COPD.
$\mathrm{P}$ eripheral skeletal muscle dysfunction is a well recognised disabling feature of chronic obstructive pulmonary disease (COPD) which manifests itself in reduced muscle strength and reduced endurance. ${ }^{1}$ Loss of muscle strength can largely be attributed to the loss of muscle bulk which, in turn, is caused by muscle fibre atrophy. ${ }^{2}$ However, loss of muscle mass does not account for the attenuated endurance, suggesting that intrinsic muscular alterations are involved as well. ${ }^{3}$ A disturbed oxidative phenotype, which is reflected by a fibre type shift from type I to II (or slow twitch to fast twitch) accompanied by reduced activities of enzymes involved in oxidative energy metabolism, ${ }^{1}$ is one of the most obvious alterations in peripheral skeletal muscles of patients with COPD.

In almost all studies examining peripheral muscle biopsies of patients with COPD, the target muscle of investigation has been the vastus lateralis (part of the quadriceps femoris). These studies, in which fibre type distribution itself was the main focus, consistently showed a reduced proportion of fibre type I in patients with COPD compared with healthy age-matched subjects. Subsequently, several biopsy studies were conducted in which muscle fibre type distribution was measured in the vastus lateralis to phenotype patients with COPD for other research questions. Surprisingly, although most of these reports present fibre type data in combination with relevant patient characteristics, very little information is available regarding the relation between fibre type proportions and hallmarks of COPD such as forced expiratory volume in $1 \mathrm{~s}\left(\mathrm{FEV}_{1}\right)$, ratio of $\mathrm{FEV}_{1}$ to forced vital capacity (FVC), carbon monoxide transfer factor (TLCO), arterial oxygen tension $\left(\mathrm{PaO}_{2}\right)$ and body mass index (BMI). This may be related to the fact that group sizes in most of these studies were too small and most studies comprised highly selected patient groups. The main objective of the current report is therefore to investigate a potential relation between fibre type proportions and markers of disease severity of COPD in a larger study population. A literature search was conducted for relevant reports from which the required data were subsequently collected and combined.

Pulmonary rehabilitation in COPD has proved to be very successful in terms of improving skeletal muscle dysfunction, exercise capacity and quality of life (evidence level A). ${ }^{4}$ Regarding the physiological properties of type I fibres (fatigue resistant but slow contraction speed) and type II fibres (low fatigue resistance but strong and fast contractions), fibre typing could be a valuable diagnostic tool for the choice and components of rehabilitation programmes such as strength or endurance training. It is therefore crucial to be able to assess when the proportion of a certain fibre type can be considered within the normal range or pathologically abnormal. However, there are few data on quadriceps fibre type distribution in the literature for healthy subjects in the age range $60-70$ years, which is the average age of patients with COPD included in most studies. Furthermore, control group sizes of the individual studies published so far are too small to make an accurate prediction. A secondary aim of the current study is therefore to define reference values for vastus lateralis fibre type proportions for the patients with COPD studied so far, using the combined data collected from the literature.

\section{METHODS}

\section{Search strategy}

Relevant electronic databases were screened to find studies in which muscle fibre type proportions have been determined in the quadriceps femoris of patients with COPD. Reviews and

Abbreviations: $B M l$, body mass index; COPD, chronic obstructive pulmonary disease; $\mathrm{FEV}_{1}$, forced expiratory volume in $1 \mathrm{~s}$; FVC, forced vital capacity; $\mathrm{MyHC}$, myosin heavy chain; $\mathrm{PaO}_{2}$, arterial oxygen tension; TLCO, carbon monoxide transfer factor 
non-human studies were excluded using available filter options and no language limitation was used. First PubMed (1966 to January 2007) was searched using the following search algorithm: (fiber-type OR fiber-types OR fibre-type OR fibretypes OR fibre OR fibres OR fiber OR fibers OR "myosin heavy chain" OR "myosin heavy chains") AND (vastus OR quadriceps OR knee-extensor OR knee-extensors OR "skeletal muscle" OR "skeletal muscles") AND (COPD OR "chronic obstructive pulmonary disease" OR emphysema OR bronchitis OR "chronic obstructive lung disease" )

A similar search algorithm was also used to screen EMBASE (1989 to January 2007) and the Cochrane Library. The electronic searches were supplemented by scanning the reference lists from retrieved articles and relevant reviews to identify additional studies that may have been missed during the initial search. Online abstracts of relevant conferences were also screened (American Thoracic Society 2001-2006 and European Respiratory Society 2001-2005). From the selected reports, fibre type composition, predicted values of $\mathrm{FEV}_{1}, \mathrm{FVC}$ and TLCO, as well as the $\mathrm{FEV}_{1} / \mathrm{FVC}, \mathrm{BMI}$ and $\mathrm{PaO}_{2}$ were collected (units were converted to those presented in table 1 when required). The primary authors of articles/abstracts published in 2000 or later were contacted for missing data whenever required and/or possible ( $\dagger$ in table 1 ). For control values of quadriceps femoris fibre type proportions we used age-matched healthy control groups of the COPD-related papers described above.

\section{Statistics}

Data are represented as mean (SD) values. In some papers the COPD groups were divided into subgroups; these were pooled to form a single group ( ${ }^{*}$ in table 1$)$ and the SD for these combined subgroups was calculated according to equation $\mathrm{l}$, where $\mathrm{SD}_{\mathrm{p}}$ is pooled standard deviation, $\mathrm{N}$ is the total sample size, $\mathrm{n}_{\mathrm{i}}$ is the sample size of the ith group, $S_{i}^{2}$ is the variance of the ith group and $\mathrm{k}$ is the number of groups:

$$
S D_{p}=\sqrt{\sum_{i=1}^{k}\left(n_{i}-1\right) s_{i}^{2} /(N-k)}
$$

\section{Inter-study analysis}

Associations (for COPD populations only) between the study average fibre type proportions and study average $\mathrm{FEV}_{1}, \mathrm{FEV}_{1}$ / FVC, Tlco, BMI, $\mathrm{PaO}_{2}$ and age were estimated using linear regression analyses with group size $(\mathrm{N})$ as weight factor. For patients with COPD and healthy controls, weighed averages (with corresponding SD according to equation l) were calculated for fibre type proportions I, IIA and IIX and the unpaired Student $t$ test was used to test whether there were differences in these fibre type proportions. A two-tailed probability value of $<0.05$ was considered statistically significant.

\section{Intra-study analysis}

Heterogeneity was tested using the Q test of homogeneity and subsequently heterogeneity was quantified using the $\mathrm{I}^{2}$ index as described by Higgens et al. ${ }^{5}$ Study-specific mean differences (MD) of fibre type proportions between control and patient groups were calculated from those papers that contained these data. The corresponding standard errors (SE) were calculated as $\left.\sqrt{(} \mathrm{SE}_{\text {controls }}^{2}+\mathrm{SE}_{\text {patients }}^{2}\right)$. A pooled $\mathrm{MD}$ was calculated by means of random effects meta-analysis using the STATA statistical software package.

\section{RESULTS}

The PubMed search for fibre types in the quadriceps femoris of patients with COPD yielded 38 citations. One additional

Table 1 Collected data from studies dealing with vastus lateralis fibre typing in COPD

\begin{tabular}{|c|c|c|c|c|c|c|c|c|c|c|c|c|}
\hline Reference & e N (M/F) & Age (y) & $\begin{array}{l}\text { BMI } \\
\left(\mathrm{kg} / \mathrm{m}^{2}\right)\end{array}$ & $\begin{array}{l}\mathrm{FEV}_{1} \\
\text { (\%pred) }\end{array}$ & $\begin{array}{l}\text { FVC } \\
\text { (\%pred) }\end{array}$ & $\mathrm{FEV}_{1} / \mathrm{FVC}(\%)$ & TLCo (\%pred) & $\mathrm{PaO}_{2}(\mathrm{kPa})$ & Type I (\%) & Type IIA (\%) & Type IIX (\%) & Fibre typing \\
\hline 13 & $14(14 / 0)$ & $66(6)^{*}$ & $28(4)^{*}$ & $31(9) \dagger$ & $64(12)^{*}$ & $43(10)^{*}$ & $60(26)^{*}$ & $9.1(0.8)^{*}$ & $30(11)^{*}$ & - & - & $\mathrm{IHC}$ \\
\hline 14 & $6(? / ?)$ & $64(9)$ & $26(4)$ & $32(11)$ & 71 (11) & $34(8)$ & - & $11.7(1.0)$ & $21(12)$ & 42 (7) & $39(3)$ & $\mathrm{HC}$ \\
\hline 15 & $19(16 / 3)$ & $65(8)^{*}$ & $26(4)^{*}$ & $42(13)^{*}$ & $79(8)^{*}$ & $43(16)^{*}$ & $49(10)^{*}$ & $8.9(0.7)^{\star}$ & $38(15)^{*}$ & $48(19)^{*}$ & $13(8)^{*}$ & $\mathrm{HC}$ \\
\hline 16 & $22(22 / 0)$ & $65(9)$ & - & $51(12)$ & 79 (17)‡ & $50(?) \ddagger \S$ & $77(27)$ & $10.8(1.1)$ & $36(17)$ & $40(13)$ & $23(22)$ & SDS PAGE \\
\hline 10 & $15(12 / 3)$ & $67(9)$ & $24(4)$ & $42(14)$ & $83(15) \dagger$ & 40 (12)† & $63(24)$ & $9.9(1.2)$ & $19(14)$ & $35(12)$ & $46(19)$ & $\mathrm{HC}$ \\
\hline 17 & $13(6 / 7)$ & $61(12)$ & $23(1)$ & 37 (12) & $75(11)$ & $36(10) \dagger$ & $47(24)$ & $9.0(1.2)$ & $25(7)$ & $47(11)$ & $28(10)$ & SDS PAGE \\
\hline 18 & $18(18 / 0)$ & $70(6)^{*}$ & $26(3)^{*}$ & $35(12)^{*}$ & $58(12)^{*}$ & $41(9)^{*}$ & - & - & $32(17)^{*}$ & $39(12)$ & 30 (11) & $\mathrm{HC}$ \\
\hline 19 & $8(8 / 0)$ & $61(5)$ & 24 (?)§ & $42(6)$ & $71(14) \ddagger$ & - & $70(14)$ & - & $44(15)$ & - & - & $\mathrm{HC}$ \\
\hline 20 & $17(17 / 0)$ & $69(5)$ & $25(3)$ & $34(12)$ & $58(14) \dagger$ & $38(7) \dagger$ & - & - & $30(14)$ & $56(15)$ & $15(14)$ & SDS PAGE \\
\hline 21 & $17(15 / 2)$ & $66(8)$ & $26(4)$ & $38(12)$ & 59 (16) & - & $66(29)$ & $10.4(1.6)$ & 31 (16) & 26 (15)t† & $27(29)$ & $\mathrm{HC} \neq \ddagger$ \\
\hline 22 & $16(? / ?)$ & $67(4)$ & $24(4)$ & 39 (16) & $63(14)$ & $39(9)$ & - & $10.4(1.2)$ & $26(12)$ & - & $20(16)$ & $\mathrm{HC}$ \\
\hline 23 & $29(20 / 9)$ & $65(5)$ & $25(5)$ & 37 (16) & 59 (16) & $43(11)$ & $56(32)$ & $10.4(1.6)$ & $27(12)$ & $32(16)$ & $22(16)^{-1}$ & $\mathrm{HC} \neq \ddagger$ \\
\hline 24 & $15(15 / 0)$ & $67(8)$ & $25(4)$ & $46(16)$ & 64 (16) & $48(12)$ & $71(20)$ & $10.9(1.7)$ & 40 (8) & $35(4)$ & $25(3)$ & $\mathrm{IHC}$ \\
\hline 25 & $32(32 / 0)$ & $64(8)^{*}$ & $28(5)^{*}$ & $42(14)^{*}$ & - & $46(9)^{*}$ & $78(21)^{*}$ & $11.3(1.8)^{*}$ & $35(12)^{*}$ & $42(13)^{*}$ & $22(11)^{*}$ & $\mathrm{HC}$ \\
\hline 26 & $9(? / ?)$ & $66(10)$ & 26 (?)ई & - & - & - & - & $8.5(2.0)$ & $29(12)$ & 35 (12) & 31 (15) & $\mathrm{HC}+\ddagger$ \\
\hline 27 & $12(12 / 0)$ & $65(5)$ & $25(3)$ & $31(9)$ & $59(16)$ & 35 (?)§ & $72(22)$ & $10.8(1.1)$ & 27 (17) & 51 (15) & $22(16)$ & SDS PAGE \\
\hline 28 & $18(13 / 5)$ & $63(7)^{*}$ & $23(?)^{\star} \S$ & $29(?)^{\star} \S$ & $67(?)^{\star} \ddagger \S$ & $34(?)^{\star} \ddagger \S$ & - & $9.2(0.9)^{*}$ & $20(11)^{*}$ & - & - & $\mathrm{HC}$ \\
\hline 29 & $20(17 / 3)$ & $65(8)$ & 26 (?)§ & 37 (11) & $61(16)$ & 40 (?)§ & $63(18)$ & $10.7(1.7)$ & $34(14)$ & 51 (15)t† & $15(12)$ & $\mathrm{HC}$ \\
\hline 8 & $29(17 / 12) \dagger$ & $63(10)$ & $22(5)$ & $39(12)$ & 69 (15) & $45(10)$ & - & $8.8(1.2) \dagger$ & $36(11)$ & $40(9)$ & $24(10)$ & $\mathrm{HC}$ \\
\hline \multicolumn{13}{|c|}{ Abstracts } \\
\hline 30 & $14(10 / 4) \dagger$ & $61(9) \dagger$ & $24(4) \dagger$ & $38(11) \dagger$ & - & $46(13) \dagger$ & $45(26) \dagger$ & - & $38(14) \dagger$ & $18(8)$ & $45(11)$ & $\mathrm{IHC}$ \\
\hline $31 / 32^{\star \star}$ & $47(47 / 0)$ & $67(8)^{* * *}$ & $24(?)^{*} \S^{\star *}$ & $40(12)^{* * *}$ & - & $41(11)^{*} \ddagger^{\star *}$ & $48(22)^{* \star \S^{* *}}$ & $9.2(1.8)^{* * *}$ & $42(8)^{*}+\uparrow+†$ & $27(5)^{\star}+\bullet+†$ & $29(7)^{*}+9+\dagger$ & $\mathrm{HC}$ \\
\hline $33 / 34^{\star *}$ & $29(29 / 0)$ & $66(6)^{* *}$ & $24(3)^{\star \star}$ & $42(13)^{* *}$ & $66(17)^{\star *}$ & $62(18) \dagger^{\star \star}$ & - & $9.1(1.0)^{\star \star}$ & $39(22)+9$ & $36(17)+9$ & $29(16)+9$ & $\mathrm{HC}$ \\
\hline
\end{tabular}

$\mathrm{N}$, study group size; BMI, body mass index; FEV , forced expiratory volume in $1 \mathrm{~s}$; FVC, forced vital capacity; TLCO, carbon monoxide transfer factor; HC, histochemistry; IHC, immunohistochemistry; SDS PAGE, gel electrophoresis analysis of myosin heavy chain isoforms; ? indicates that the data were not given or could not be calculated.

*Calculated from combined subgroups.

†Additional data obtained from authors through personal communication, used with permission.

$\ddagger$ Vital capacity instead of forced vital capacity.

$\S$ Calculated from average data as presented in the paper.

- Not all subjects had a muscle biopsy.

**Data obtained from a related publication.

††Determined in a figure.

$\$ ¥$ Sum of fibre type proportions is not $100 \%$ because (small) proportions of hybrid fibres were excluded from analysis. 
Potentially relevant studies retrieved from databases $(n=42)$
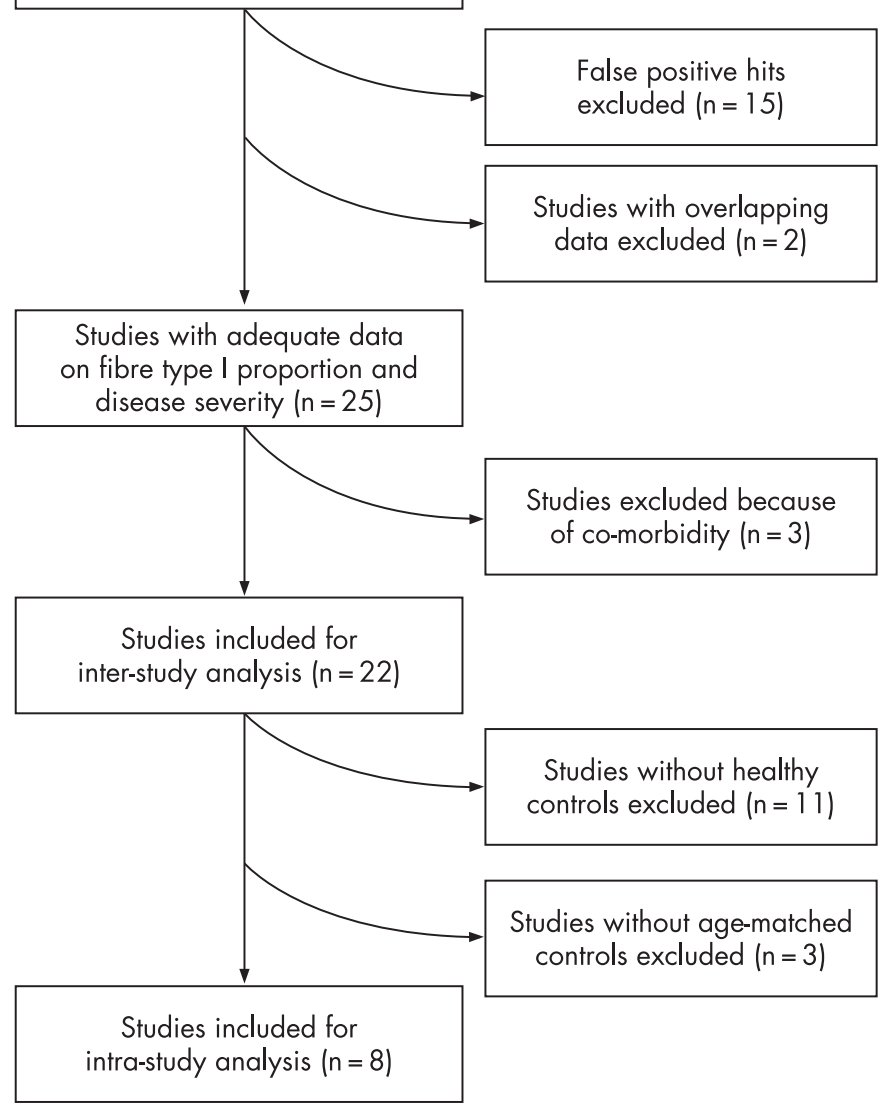

Figure 1 Flow diagram of study inclusion for the inter-study and intrastudy analyses.

publication, of which we were aware, incorrectly did not appear in the search results because fibre typing was not mentioned in the abstract. ${ }^{6}$ Of these 39 papers, 20 were excluded for the following reasons: 15 were false positive hits (eg, fibre type proportions were not studied or they were studied in skeletal muscles other than the quadriceps femoris), 2 had overlapping data (Montes de Oca $e a l^{78}$ and Gosker et $a l^{9}{ }^{10}$ ) and 3 because of co-morbidity. ${ }^{6}{ }^{11} 12$ The remaining 19 articles were included in the current study (table 1), all biopsies being obtained from the vastus lateralis. Data from relevant conference abstracts was most often already published in the full articles that were found. However, 3 abstracts contained data not (yet) published elsewhere and these were therefore also included (table 1). The search in EMBASE and the Cochrane Library did not yield any citations in addition to those found in PubMed or the online conference abstracts. The inclusion process is shown in fig 1 . The collected data are presented in table 1 .

\section{Inter-study analysis}

In patients with COPD there was a strong positive association between the percentage predicted $\mathrm{FEV}_{1}$ and the proportion of fibre type I $(r=0.56 ; \mathrm{p}<0.001$; fig $2 \mathrm{~A})$ and between the $\mathrm{FEV}_{1} /$ FVC and the proportion of fibre type I $(r=0.57 ; \mathrm{p}<0.001$; fig $2 \mathrm{~B})$. BMI was moderately associated with the proportion of fibre type I ( $r=0.34 ; \mathrm{p}<0.001$; fig $2 \mathrm{~F})$ and TLCo was weakly but significantly associated with the proportion of fibre type I $(r=-0.15 ; \mathrm{p}=0.013 ;$ fig $2 \mathrm{C})$. There were no significant relations between $\mathrm{PaO}_{2}$ or age and the proportion of fibre type I (fig 2D and E). Because fibre types are always expressed proportionally to each other, opposite relations are per definition true for the total fibre type II proportion. However, most of the 22 studies also distinguished between type IIA and IIX fibres and some weak to moderate relations were found. The proportion of fibre type IIA was negatively associated with percentage predicted $\mathrm{FEV}_{1}(r=-0.2 \mathrm{l} ; \mathrm{p}<0.001), \mathrm{FEV}_{1} / \mathrm{FVC}$ $(r=-0.32 ; \mathrm{p}<0.001)$ and BMI $(r=-0.14 ; \mathrm{p}=0.010)$ and was positively associated with TLCo $(r=0.37 ; \mathrm{p}<0.001)$ and $\mathrm{PaO}_{2}$ $(r=0.18 ; \mathrm{p}=0.002)$. The proportion of fibre type IIX was positively associated with $\mathrm{FEV}_{1} / \mathrm{FVC}(r=0.25 ; \mathrm{p}<0.001)$ and TLCO $(r=0.31 ; \mathrm{p}<0.001)$.

Compared with the healthy age-matched controls (table 2), the overall fibre type I proportion was reduced in patients with COPD (51 (12)\% vs 33 (14)\%; p=0.004) and the fibre type IIX proportion was increased ( $13(8) \%$ vs $26(14) \% ; p=0.006)$. The proportion of fibre type IIA tended to be higher (7\%) in COPD, but this did not reach statistical significance.

\section{Intra-study analysis}

From the 22 selected studies, 11 included fibre type data of a healthy control group. In 3 of these studies the control group was not age-matched, ${ }^{16}{ }^{19} 20$ and these studies were therefore excluded from this analysis (see flow diagram in fig 1). The Q test of homogeneity indicated that there was no heterogeneity (fibre type I: $\mathrm{Q}=10.261, \mathrm{p}=0.17$; fibre type IIA: $\mathrm{Q}=8.467$, $\mathrm{p}=0.2 \mathrm{l}$; fibre type IIX: $\mathrm{Q}=9.98, \mathrm{p}=0.19)$. However, an $\mathrm{I}^{2}$ index of about $30 \%$ (32\%, 29\% and 30\% for fibre types I, IIA and IIX, respectively) was found. Because this indicates that $30 \%$ of the variance can still be explained by heterogeneity, it was decided to use a random effects model. The results of the metaanalysis based on the 8 remaining studies (table 2) for fibre type proportions are shown in fig 3. The pooled mean differences between patients and control groups in type I, IIA and IIX fibre proportions were $22(5) \%,-7(4) \%$ and $-13(4) \%$, respectively.

\section{DISCUSSION}

To date it is unclear whether changes in lower limb muscle fibre type distribution in COPD are related to disease severity. The most prominent marker of disease severity is the $\mathrm{FEV}_{1}{ }^{35}$ but, surprisingly, most of the currently reviewed papers did not mention a relation between $\mathrm{FEV}_{1}$ and fibre type proportion. In the current review all the group data of these individual studies were pooled, and when the $\mathrm{FEV}_{1}$ was plotted against fibre type I proportion it became clear that the fibre type I proportion in the vastus lateralis of patients with COPD decreases with increasing disease severity. This relation also exists for the $\mathrm{FEV}_{1}$ corrected for the FVC. The currently observed positive relation between BMI and fibre type I proportion further underlines the fact that the proportion of fibre type I declines with increasing disease severity, considering low BMI as an important marker of systemic disease severity. ${ }^{36}$ For fibre type II these relations are inverse, by the definition of fibre type proportions. Inverse associations between the proportion of fibre type IIA and markers of disease severity were indeed found, but not for the proportion of fibre type IIX.

There are, however, some unexplored areas. From this review it became clear that most studies focused on GOLD stages 3 and 4 (patients with more severe COPD). To study the natural course of muscle impairment in COPD it would be interesting to investigate muscle fibre type distribution in patients with mild to moderate COPD (stages 1 and 2). The current review also suggests that there is no relationship between fibre type proportion and the $\mathrm{PaO}_{2}$. However, hardly any patients with severe hypoxaemia $\left(\mathrm{PaO}_{2}<7.3 \mathrm{kPa}\right)$ were studied. It is thus possible that severe hypoxaemia contributes to altered fibre type proportion in the limb musculature of patients with COPD, 

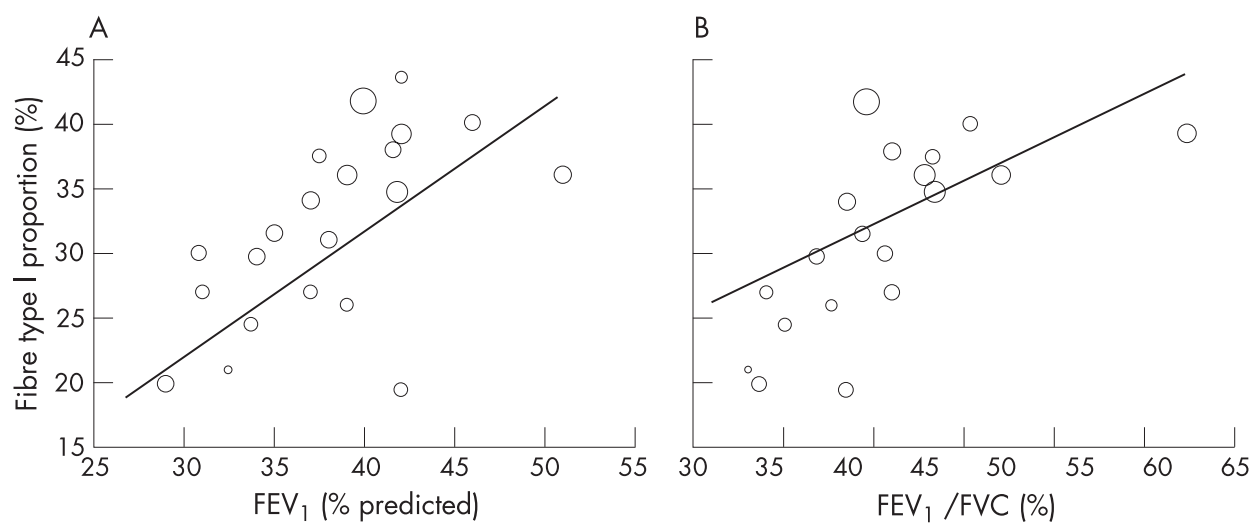

Figure 2 Relationships between vastus lateralis fibre type I proportion and $(A)$ forced expiratory volume in $1 \mathrm{~s}\left(\mathrm{FEV}_{1}\right)$; (B) ratio of $F E V_{1}$ to forced vital capacity (FVC)

(C) carbon monoxide transfer factor (TLCO); (D) arterial oxygen tension $\left(\mathrm{PaO}_{2}\right)$; (E) age; and (F) body mass index (BMI). Circle sizes represent group sizes. Solid lines represent the weighted linear regression lines (if statistically significant only). Bold circles appear in cases of two overlaying identical data sets.
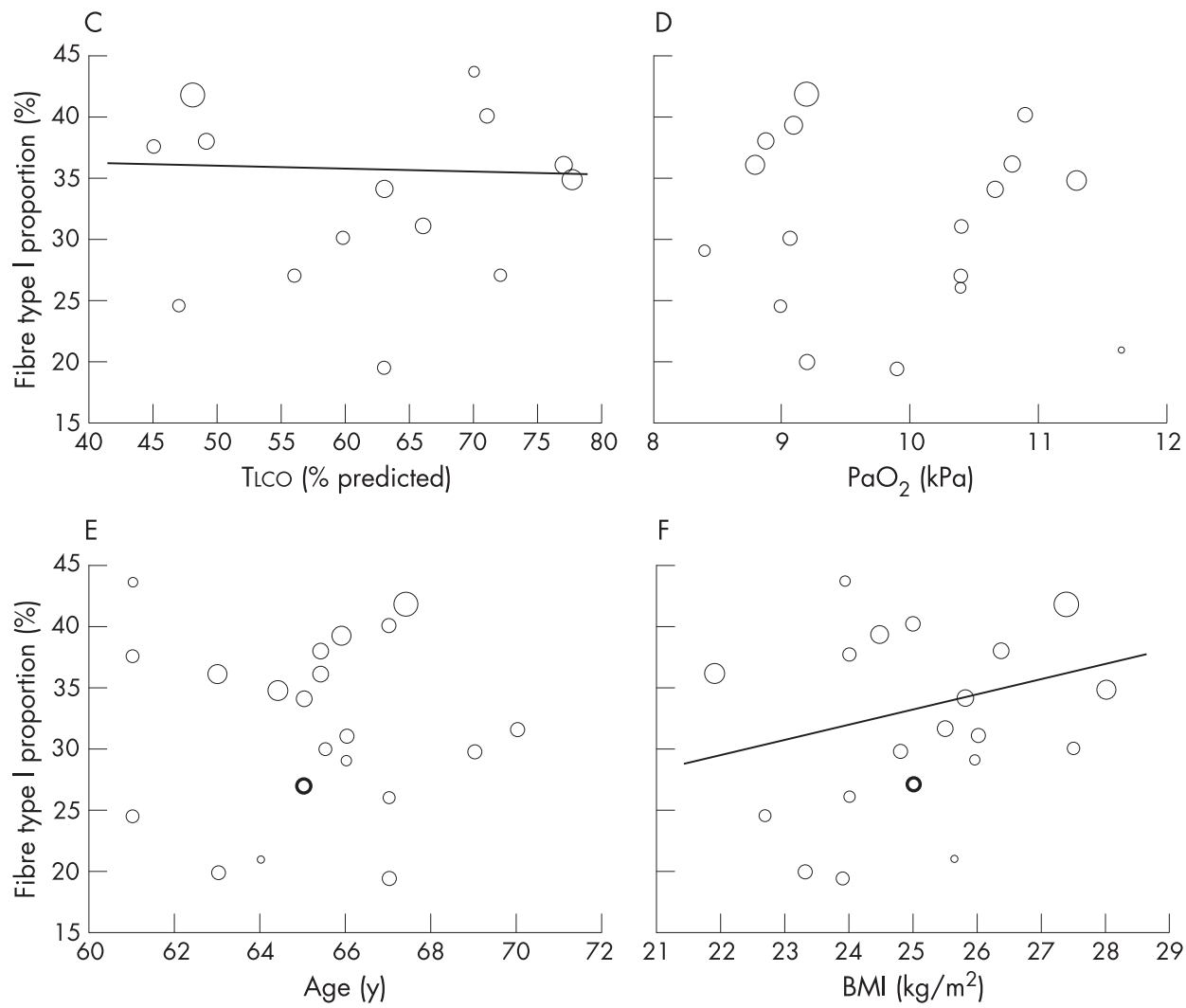

and therefore fibre type data from this specific subgroup of patients are required. Moreover, patients with moderate hypoxaemia may suffer from frequent desaturations during exercise or sleep and the effect of intermittent hypoxaemia on muscle abnormalities in COPD has never been studied. With respect to cachexia, the only indicator frequently reported in the included studies was the BMI. As mentioned earlier, the currently observed relation between BMI and fibre type I

Table 2 Vastus lateralis fibre typing in healthy age-matched controls

\begin{tabular}{|c|c|c|c|c|c|c|}
\hline Reference & $N(M / F)$ & Age (years) & Type I (\%) & Type IIA (\%) & Type IIX (\%) & Fibre typing \\
\hline 29 & $9(9 / 0)$ & $65(5)$ & $58(16)$ & 32 (13)† & $5(5)$ & $\mathrm{HC} \ddagger$ \\
\hline 27 & $10(10 / 0)$ & $61(6)$ & 41 (9) & $39(9)$ & $20(9)$ & SDS PAGE \\
\hline 10 & $15(13 / 2)$ & 64 (3) & 43 (13) & 29 (12) & 27 (12) & $\mathrm{HC}$ \\
\hline 24 & $7(7 / 0)$ & $63(9)$ & $62(2)$ & $28(5)$ & $10(8)$ & $\mathrm{IHC}$ \\
\hline 23 & $18(15 / 3)$ & 65 (4) & $58(12)^{*}$ & $29(12)^{*}$ & $8(8)^{*}$ & $\mathrm{HC} \neq$ \\
\hline 21 & $10(10 / 0)$ & $61(6)$ & 54 (13) & $28(16) \dagger$ & $8(6)$ & $\mathrm{HC} \ddagger$ \\
\hline 22 & $9(9 / 0)$ & $63(5)$ & $39(11)^{*}$ & - & $8(4)^{\star}$ & $\mathrm{HC}$ \\
\hline 14 & $6(? / ?)$ & 65 (11) & $50(14)^{*}$ & $36(21)^{*}$ & $16(10)^{*}$ & $\mathrm{HC}$ \\
\hline
\end{tabular}

$\mathrm{N}$, study group size; HC, histochemistry; IHC, immunohistochemistry; SDS PAGE, gel electrophoresis analysis of myosin heavy chain isoforms; ? indicates that the data were not given.

*Not all subjects had a muscle biopsy.

†Determined in a figure.

†Sum of fibre type proportions is not $100 \%$ because (small) proportions of hybrid fibres were excluded from the analysis. 

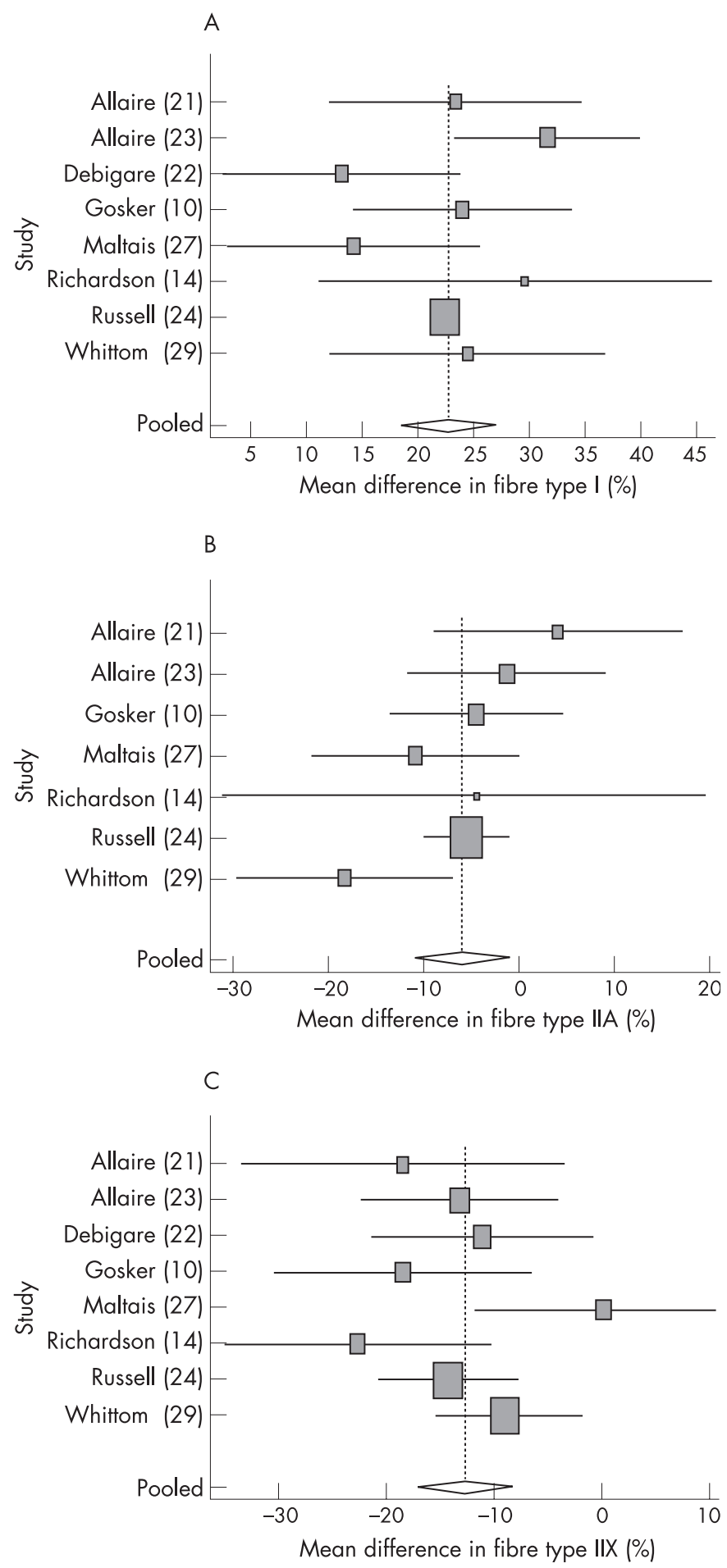

Figure 3 Forest plot showing the results of the random effects metaanalysis for the mean differences in (A) muscle fibre type I proportion; (B) muscle fibre type IIA proportion; and (C) muscle fibre type IIX proportion between control and patient groups. Box sizes represent quality of the study as $1 / \sqrt{ }$ SE. Note that IIA data were not provided in one of the eight studies. ${ }^{22}$

proportion underscores an association between the proportion of fibre type I and disease severity. However, muscle tissue is located in the fat-free mass compartment. Fat-free mass has recently been identified as a better predictor of mortality and thus as a marker of systemic disease than BMI in COPD. ${ }^{37}$ Although BMI was weakly associated with fibre types, it remains unclear to what extent muscle wasting per se contributes to fibre type redistribution in COPD. Another aspect that is unclear to date is whether fibre type redistribution is comparable between the COPD subtypes emphysema and chronic bronchitis. The TlCo generally is lower in the emphysema subtype. Although there was a weak but statistically significant association between TLCO and fibre type proportions in the current review, the association between muscle fibre type composition and emphysema requires further investigation using more sensitive markers such as high resolution CT scanning.

An additional value of the current research is that solid reference values for fibre type proportions in healthy subjects in the typical age range (60-70 years) for COPD GOLD stages 3-4 can now be provided. Individual studies have consistently shown a reduced proportion of fibre type I in vastus lateralis biopsies from patients with COPD which was clearly confirmed in the current study. The inter-study analysis revealed a mean difference of $22 \%$ and the intra-study analysis resulted in a similar difference of $18 \%$. Likewise, the proportion of fibre type IIX was $13 \%$ higher in patients with COPD in both analyses. However, taking into account the large variation in human muscle fibre type composition, ${ }^{38}$ we questioned what fibre type proportions can really be considered as pathologically abnormal. Based on the pooled mean of the included control groups, a $\mathrm{p}$ value of 0.05 and an assumed normal distribution, a fibre type I proportion $<27 \%(51 \%-1.96 \times 12 \%)$ can be considered as abnormally low. Likewise, a fibre type IIX proportion $>29 \%$ $(13 \%+1.96 \times 8 \%)$ can be regarded as abnormally high. These results were confirmed when the eight control groups were extended with age-matched control groups from nine additional non-COPD related papers (data not shown). These findings may have diagnostic value for identifying muscle pathology as a therapeutic target.

In the included studies, several techniques for the determination of fibre type proportions have been used, but they all have in common that the distinction is based on the content of myosin heavy chain (MyHC) isoforms I, IIA and IIX. The most classic method is based on histochemical staining of the MyHC ATPase activity after selective inhibition of the ATPase domains. Alternatively, immunohistochemistry can be applied using antibodies raised against the different MyHC isoforms. Another approach is to homogenise muscle tissue and separate the MyHC isoforms by gel electrophoresis followed by quantification of the band intensities after, for example, silver staining or western blotting. It is worth mentioning that, when only studies in which fibre types were assessed using histochemistry were included in the analyses, the overall outcomes did not change (data not shown).

It must be acknowledged that, in the present report, interpretations of statistical data were made in which inferences about the nature of individuals were based on aggregate between-study statistics collected for the group to which those individuals belong. In theory, these interpretations could therefore be incorrect (referred to as the ecological fallacy). The best solution to these issues would be to collect the data of all the individuals in the included studies. However, the associations between fibre type proportions and the $\mathrm{FEV}_{1}$ or $\mathrm{FEV}_{1} / \mathrm{FVC}$ are quite convincing. Moreover, the fact that the pooled mean differences in fibre type proportions calculated from the meta-analysis (the intra-study analysis) are similar to the differences calculated from the pooled control values and pooled COPD values (inter-study analysis) suggests that ecological fallacy does not play a significant role.

This systematic review shows that the reduction in the proportion of fibre type I that occurs in the lower limb muscle of patients with COPD is strongly associated with disease severity. In addition, we provide a reliable indication of what can be considered as a reference (physiological) fibre type 
composition in the typical COPD age range of $60-70$ years, beyond which this can be considered as muscle pathology.

\section{Authors' affiliations}

Harry R Gosker, Emiel F M Wouters, Annemie M W J Schols, Department of Respiratory Medicine, Nutrition and Toxicology Research Institute Maastricht (NUTRIM), Maastricht University, The Netherlands

Maurice P Zeegers, Unit of Genetic Epidemiology, Department of Public Health \& Epidemiology, University of Birmingham, UK

The research of HRG was supported by an award from the Netherlands Asthma Foundation (project number 3.2.05.038).

Competing interests: None.

\section{REFERENCES}

1 ATS/ERS. Skeletal muscle dysfunction in chronic obstructive pulmonary disease. A statement of the American Thoracic Society and European Respiratory Society. Am J Respir Crit Care Med 1999;159:S1-40.

2 Gosker HR, Engelen MPKJ, van Mameren H, et al. Muscle fiber type IIX atrophy is involved in the loss of fat-free mass in chronic obstructive pulmonary disease. Am J Clin Nutr 2002;76:113-9.

3 Gosker HR, Lencer NHMK, Franssen FME, et al. Striking similarities in systemic factors contributing to decreased exercise capacity in patients with severe chronic heart failure or COPD. Chest 2003;123:1416-24.

4 Berry MJ, Rejeski WJ, Adair NE, et al. Exercise rehabilitation and chronic obstructive pulmonary disease stage. Am J Respir Crit Care Med 1999; 160:1248-53.

5 Higgins JP, Thompson SG. Quantifying heterogeneity in a meta-analysis. Stat Med 2002;21:1539-58

6 Barreiro E, Gea J, Corominas JM, et al. Nitric oxide synthases and protein oxidation in the quadriceps femoris of patients with chronic obstructive pulmonary disease. Am J Respir Cell Mol Biol 2003;29:771-8.

7 Montes de Oca M, Torres SH, Gonzalez Y, et al. Changes in exercise tolerance, health related quality of life, and peripheral muscle characteristics of chronic obstructive pulmonary disease patients after 6 weeks' training. Arch Bronconeumol 2005:41:413-8.

8 Montes de Oca M, Torres SH, Gonzalez Y, et al. Peripheral muscle composition and health status in patients with COPD. Respir Med 2006;100:1800-6

9 Gosker HR, Schrauwen P, Hesselink MKC, et al. Uncoupling protein-3 content is decreased in peripheral skeletal muscle of patients with COPD. Eur Respir $J$ 2003;22:88-93.

10 Gosker HR, van Mameren H, van Dijk PJ, et al. Skeletal muscle fibre type shifting and metabolic profile in patients with COPD. Eur Respir J 2002;19:617-26.

11 Doucet M, Debigare R, Joanisse DR, et al. Adaptation of the diaphragm and the vastus lateralis in mild-to-moderate COPD. Eur Respir J 2004;24:971-9.

12 Engelen MP, Orozco-Levi M, Deutz NE, et al. Glutathione and glutamate levels in the diaphragm of patients with chronic obstructive pulmonary disease. Eur Respir J 2004;23:545-51.

13 Ramirez-Sarmiento A, Orozco-Levi M, Guell R, et al. Inspiratory muscle training in patients with chronic obstructive pulmonary disease: structural adaptation and physiologic outcomes. Am J Respir Crit Care Med 2002;166:1491-7.

14 Richardson RS, Leek BT, Gavin TP, et al. Reduced mechanical efficiency in chronic obstructive pulmonary disease but normal peak $\mathrm{VO}_{2}$ with small muscle mass exercise. Am J Respir Crit Care Med 2004;169:89-96.

15 Vogiatzis I, Terzis G, Nanas S, et al. Skeletal muscle adaptations to interval training in patients with advanced COPD. Chest 2005; 128:3838-45.
16 Satta A, Migliori GB, Spanevello A, et al. Fibre types in skeletal muscles of chronic obstructive pulmonary disease patients related to respiratory function and exercise tolerance. Eur Respir J 1997;10:2853-60.

17 Gosker HR, Schrauwen P, Broekhuizen R, et al. Exercise training restores uncoupling protein-3 content in limb muscles of patients with chronic obstructive pulmonary disease. Am J Physiol Endocrinol Metab 2006;290:E976-81.

18 Koechlin C, Maltais F, Saey D, et al. Hypoxaemia enhances peripheral muscle oxidative stress in chronic obstructive pulmonary disease. Thorax 2005:60:834-41.

19 Jobin J, Maltais F, Doyon JF, et al. Chronic obstructive pulmonary disease: capillarity and fiber-type characteristics of skeletal muscle. J Cardiopulm Rehabil 1998; 18:432-7.

20 Hayot M, Michaud A, Koechlin C, et al. Skeletal muscle microbiopsy: a validation study of a minimally invasive technique. Eur Respir J 2005;25:431-40

21 Allaire J, Maltais $F$, LeBlanc $P$, et al. Lipofuscin accumulation in the vastus lateralis muscle in patients with chronic obstructive pulmonary disease. Muscle Nerve 2002;25:383-9.

22 Debigare $\mathrm{R}$, Cote $\mathrm{CH}$, Hould FS, et al. In vitro and in vivo contractile properties of the vastus lateralis muscle in males with COPD. Eur Respir J 2003;21:273-8.

23 Allaire J, Maltais F, Doyon JF, et al. Peripheral muscle endurance and the oxidative profile of the quadriceps in patients with COPD. Thorax 2004:59:673-8.

24 Russell AP, Somm E, Debigare R, et al. COPD results in a reduction in UCP3 long mRNA and UCP3 protein content in types I and lla skeletal muscle fibers. J Cardiopulm Rehabil 2004;24:332-9.

25 Saey D, Michaud A, Couillard A, et al. Contractile fatigue, muscle morphometry and blood lactate in chronic obstructive pulmonary disease. Am J Respir Crit Care Med 2005; 171:1109-15.

26 Hildebrand IL, Sylvén C, Esbiörnsson M, et al. Does chronic hypoxaemia induce transformations of fibre types? Acta Physiol Scand 1991;141:435-9.

27 Maltais $F$, Sullivan MJ, LeBlanc $P$, et al. Altered expression of myosin heavy chain in the vastus lateralis muscle in patients with COPD. Eur Respir J 1999;13:850-4.

28 Jakobsson $\mathbf{P}$, Jorfeldt L, Brundin A. Skeletal muscle metabolites and fibre types in patients with advanced chronic obstructive pulmonary disease (COPD), with and without chronic respiratory failure. Eur Respir J 1990;3:192-6.

29 Whittom F, Jobin J, Simard PM, et al. Histochemical and morphological characteristics of the vastus lateralis muscle in patients with chronic obstructive pulmonary disease. Med Sci Sports Exerc 1998;30:1467-74.

30 Fuld JP, Awede A, Neder JA, et al. Skeletal muscle histology and functional capacity in COPD patients (abstract). Eur Respir J 2002;20:289s.

31 Fournier M, Casaburi R, Storer T, et al. Cellular and molecular adaptations in skeletal muscle to testosterone and/or resistence training in men with COPD (abstract). Am Respir J Crit Care Med 2004;169:A904.

32 Casaburi R, Bhasin S, Cosentino L, et al. Effects of testosterone and resistance training in men with chronic obstructive pulmonary disease. Am J Respir Crit Care Med 2004;170:870-8.

33 Svartberg J, Aasebo U, Toft I, et al. Testosterone supplementation in men with COPD and muscle morphology (abstract). Eur Respir J 2005;26:659s.

34 Svartberg J, Aasebo U, Hjalmarsen A, et al. Testosterone treatment improves body composition and sexual function in men with COPD, in a 6-month randomized controlled trial. Respir Med 2004;98:906-13.

35 Fabbri LM, Pauwels RA, Hurd SS, et al. Global strategy for the diagnosis, management, and prevention of chronic obstructive pulmonary disease: GOLD Executive Summary updated 2003. COPD 2003;2004:105-41.

36 Celli BR, Cote CG, Marin JM, et al. The body-mass index, airflow obstruction, dyspnea, and exercise capacity index in chronic obstructive pulmonary disease. N Engl J Med 2004;350:1005-12.

37 Schols AM, Broekhuizen R, Weling-Scheepers CA, et al. Body composition and mortality in chronic obstructive pulmonary disease. Am J Clin Nutr 2005;82:53-9.

38 Toft I, Lindal S, Bonaa $\mathrm{KH}$, et al. Quantitative measurement of muscle fiber composition in a normal population. Muscle Nerve 2003;28:101-8.

\section{Keep up to date: sign up for our alerting services}

Find out automatically when an article is published on a specific topic or by a particular author. We can also alert you when an article is cited or if an eletter or correction is published. You can also choose to be alerted when a new issue is published online [and when we post articles Online First]. Check out the New Content Alerts and Citation tracker from the Online tools section on the home page. 